\title{
Prevalence and risk factors of bovine and ovine fasciolosis, and evaluation of direct sedimentation sensitivity method at Bahir-Dar Municipal Abattoir, Northern Ethiopia
}

\author{
Ayalew Sisay ${ }^{1}$ and Endalkachew Nibret ${ }^{2}$ \\ ${ }^{1}$ Department of Biology, College of Natural and Computational Science, Debre Markos University, \\ P.O.Box 269, Debre Markos \\ ${ }^{2}$ Department of Biology, Science College, Bahir Dar University, P.O.Box 79, Bahir Dar, Ethiopia \\ *Corresponding author
}

\begin{abstract}
A cross-sectional study was conducted from November, 2010 to March, 2011 to estimate the prevalence of bovine and ovine fasciolosis, to assess risk factors and to estimate direct financial loss due to liver condemnation on cattle and sheep slaughtered at Bahir Dar municipal abattoir. Additionally, the sensitivity of direct sedimentation technique for the diagnosis of fasciolosis in cattle and sheep was also evaluated. Thus, of the total 768 collected fecal samples (384 cattle and 384 sheep), 121 cattle (31.5\%) and 42 sheep (10.9\%) were found positive. Likewise, detail postmortem examination of the livers revealed significant $(\chi 2=72.17 ; p=0.000)$ difference in the number of flukes recovered from cattle (45.3\%) and sheep (16.9\%). Analysis of the risk factors indicated the presence of significant occurrence of ovine fasciolosis among different age groups $\left(p=0.038, \chi^{2}=4.30\right)$ and between sexes $(p=0.710, \chi 2=0.14)$. Analysis of intensity of pathological lesion in bovine livers revealed 43 (24.7\%) lightly, 71 (40.8\%) moderately, and 60 (34.5\%) severely affected livers. Fasciola hepatica was more prevalent (69.5 and 76.9\%) than Fasciola gigantica (14.4 and 13.9\%), mixed infection by both flukes ( 6.9 and $6.2 \%)$ and unidentified immature fluke (16.0 and $9.2 \%)$ in cattle and sheep, respectively. The sensitivity and specificity of fecal examination were found to be $69.54 \%$ and $100 \%$ in cattle and $64.61 \%$ and $100 \%$ in sheep, respectively. The average financial loss per annum as a result of liver condemnation was estimated to be 198,457.80 and 3,745.76 Ethiopian Birr (11421.61 and 215.56 USD) in cattle and sheep, respectively, indicating that the disease is economically important. This study showed high prevalence of fasciolosis occurrence associated with high financial losses implying the need for control intervention.
\end{abstract}

Keywords: Fasciolosis, prevalence, sheep, cattle, abattoir, economic importance, Ethiopia

http://dx.doi.org/10.4314/evj.v17i2.1 


\section{Introduction}

Parasitism represents a major obstacle to the development of sub-sectors of livestock (Malone et al., 1998). Fasciolosis is an economically important disease of sheep, cattle, goat and occasionally human beings (Andrews, 1999) and thus considered as zoonotic infection (WHO, 1995). The disease is caused by trematodes of the genus Fasciola. The two species of the greater Veterinary importance for the disease fasciolosis are Fasciola hepatica and Fasciola gigantica (Hansen and Perry, 1994). Fasciolosis, caused by Fasciola hepatica and $F$. gigantica, is one of the most prevalent helminth infections of ruminants in different parts of the world (Soulsby, 1982). Fasciolosis is the most prevalent parasitic disease of sheep in the highlands of Ethiopia (Brook Lemma, 1983). Fasciola hepatica has a worldwide distribution mainly in the temperate climates compared to F. gigantica which is distributed in tropical countries (FAO, 2003).

The disease is responsible for considerable economic losses in the cattle industry, mainly through mortality, liver condemnation, reduced production of meat, milk, and wool, and expenditure for antihelmintics (Hillyer and Apt, 1997). The prevalence of fasciolosis in many parts of Africa has been determined mainly at slaughter. The disease causes economic loss in sheep and cattle of Africa mainly through liver condemnation. A study conducted by Keyyu et al. (2006) reported up to $100 \%$ liver condemnation rates in some slaughter slabs in Iringa region Tanzania due to liver flukes in cattle. A number of studies have been conducted with regard to abattoir based prevalence and assessment of the economic loss due to fasciolosis in different parts of Ethiopia (Taddele Tollesa and Worku Tigre, 2007; Tariku Jibat et al., 2008; Gebretsadik Berhe et al., 2009). Accurate assessment of the prevalence of the disease requires employment of different diagnosis techniques. Among these, direct sedimentation is the most commonly used diagnosis technique for prevalence studies. This method, however, has not been evaluated for its diagnostic efficiency in Bahir Dar municipal abattoir for the study of fasciolosis in and around Bahir Dar. Therefore, this study was designed to assess the prevalence of bovine and ovine fasciolosis, to investigate some of the potential risk factors, to identify the dominant species of Fasciola in the study area in bovine and ovine, to compare fluke burden and intensity of liver lesions, to measure the diagnostic efficiency of fecal examination taking the postmortem inspection as gold standard and to assess financial loss incurred due to condemned livers by fasciolosis in bovine and ovine. 


\section{Materials and Methods}

Study area

The study was conducted at Bahir Dar, the capital of Amhara National Regional State located at the geographic coordinates of $11^{\circ} 38^{\prime}$ North latitudes and $37^{\circ} 15^{\prime}$ East longitudes. The city is found at the distance of $567 \mathrm{~km}$ away from Addis Ababa to the Northern parts of the country. According to Meteorological Agency, Bahir Dar has a mean annual rainfall of about $1384 \mathrm{~mm}$ and mean annual temperature of $16^{\circ} \mathrm{C}$.

\section{Study Type}

A cross-sectional study was conducted from November, 2010 to March, 2011 on the animals that were randomly sampled and examined by antemortem and postmortem examination.

Study animals

The study was conducted on cattle and sheep that were slaughtered at Bahir-Dar Municipal Abattoir. These animals were mainly coming from the Southern parts of Gondar, West parts of Gojam such as Adet, Durbete and Merawi representing different agro-ecologies. It was difficult to trace precisely back the geographical origins of some of the animals due to the lack of reliable animal identification method to relate the findings to a particular locality.

Sample size determination

To determine the sample size, prevalence of $50 \%$ for cattle and sheep at Bahir Dar were taken into consideration. The desired sample size for the study was calculated using the formula given by Thrusfield (1995) with $95 \%$ confidence interval and at $5 \%$ absolute precision.

$$
\mathrm{n}=\frac{1.96^{2} \mathrm{p} \exp \left(1-\mathrm{p}_{\mathrm{exp}}\right)}{\mathrm{d}^{2}}
$$

$\mathrm{n}=$ required sample size

Pexp $=$ expected prevalence

$\mathrm{d}=$ desire $\mathrm{d}$ absolute precision 
Ayalew Sisay, et al.

Sampling procedure

Systematic random sampling method was employed until the required sample size was reached.

Study methodology

Antemortem inspection

Antemortem inspections were conducted on individual animals, while they were in the lairage. Cattle sent for slaughter were all male and adult, and then preslaughter examinations were conducted based on Body Condition Score (BCS). Regarding sheep, pre-slaughter examinations were conducted based on sex, age and Body Condition Score. Both sides of the animals were inspected at rest and in motion. Following the judgments passed by FAO (1994), animals fit for human consumption were allowed for slaughter. Prior to slaughter, faecal samples were collected directly from the rectum of each study animal, using disposable plastic gloves and placed in clean universal bottle and each sample was clearly labeled with animal identification, sex, age and body condition score. Faecal samples were preserved with $10 \%$ formalin solution to avoid the eggs developing and hatching. In the laboratory, coproscopy was used to detect the presence of Fasciola eggs using the standard sedimentation techniques recommended by Hansen and Perry (1994). Abattoir based prevalence was used to determine positivity of the animals for the disease, but coproscopy was used to compare the diagnostic efficiency of the disease with postmortem examination.

\section{Postmortem examination}

The prevalence of fasciolosis was conducted by postmortem examination technique from liver parenchyma and major bile ducts to recover the young flukes and adult parasites, respectively. The previously identified animals and their livers were carefully supervised and examined, so as to avoid mixing up of the organs to be inspected with the faecal samples. Postmortem examination of liver and associated bile duct was carefully performed by visualization and palpation of the entire organ followed by transverse incision of the org an across the thin left lobe in order to confirm the presence of the parasites (Urquhart et al., 1996).

Liver fluke burden and degree of pathological lesions

Fluke burden was determined by counting the recovered Fasciola parasite following the approach of Hammond and Sewell (1974). The liver was cut into 
slices of about $1 \mathrm{~cm}$ thick and put in a metal trough and then the heads of the flukes were counted. Pathological lesion categorization of the affected livers was undertaken on the basis of the intensity of lesions. Affected livers were grouped into three categories as per the criteria previously described by Ogunrinade and Adegoke (1982) as lightly affected: if quarter of the organ is affected, moderately affected: if half of the org an is affected and two or more bile ducts are hyperplastic, and severely affected: if almost the entire organ is affected and the right lobe is often atrophied. The presence of more than 50 flukes per liver indicates high pathogenicity (Soulsby, 1982).

Pathological lesions were judged and differentiated according to guidelines on meat inspection for developing countries and the decisions at postmortem inspection are classified into the following categories of judgment such as approved as fit for human consumption, conditionally approved as fit for human consumption and totally condemned as unfit for human consumption (FAO, 1994). Comparison between the severity of liver lesions and intensity of fluke burden (worm load) was conducted only on 174 condemned livers of cattle due to the chronic nature of fasciolosis in bovine which clearly shows an increase in liver size unlike the acute nature of the disease which does not show a clear change in ovine.

\section{Fasciola species identification}

For Fasciola species identification, one or more samples of the worms were collected from condemned livers which had active infection. Species identification was conducted on recovered Fasciola based on morphological features of the agents and classified into Fasciola hepatica, Fasciola gigantic, mixed infection by both flukes and unidentified or immature forms of liver fluke (Urquhart et al., 1996).

\section{Assessment of direct economic loss due to liver condemnation}

A number of parameters were used to estimate the losses attributable to liver condemnations in slaughtered cattle and sheep. Such parameters included the annual slaughter rate of 10950 cattle at the abattoir and 4425 sheep at Azwa Hotel. Condemnation rates of cattle and sheep liver due to fasciolosis were taken into consideration. The average selling price of cattle and sheep livers was established through a survey which was conducted in various meat shops at Bahir Dar town. A total of 10 livers for each adult cattle and sheep were weighed immediately after slaughter using weighing balance to get average weight. The average weights of livers were $4 \mathrm{Kg}$ in adult cattle and $0.25 \mathrm{Kg}$ in sheep; and average cost of $10 \mathrm{Birr} /$ 
$\mathrm{Kg}$ and $20 \mathrm{Birr} / \mathrm{Kg}$ for each cattle and sheep liver, respectively. Records of total number of animals slaughtered and the liver lesions observed and condemned were collected. All affected livers were rejected, since partial approval was not practiced in the abattoirs. The direct financial losses due to liver condemnation were estimated by the formula set by Ogunrinade and Ogunrinade (1980).

Total annual liver condemnation $(\mathrm{ALC})=\mathrm{MCS} \times \mathrm{MLC} \times \mathrm{Prev}$

Where:

$\mathrm{ALC}=$ Annual liver condemnation

MCS $=$ Mean annual cattle slaughtered per year at Bahir Dar Municipal Abattoir

$\mathrm{MLC}=$ Mean cost of one liver in Bahir Dar town

Prev $=$ Prevalence of totally condemned liver due to fasciolosis in the abattoir.

Comparing the diagnostic efficiency of faecal and postmortem examination

The sensitivity and specificity of the method was computed by taking liver inspection at postmortem as gold standard for the diagnosis of fasciolosis. Kappa statistic was used to determine the degree of agreement between the two methods of liver fluke diagnosis. The Kappa value was interpreted as: slight agreement $(\mathrm{K}<$ $0.2)$; fair agreement $(\mathrm{K}=0.2-0.4)$; moderate agreement $(\mathrm{K}=0.4-0.6)$; substantial agreement $(\mathrm{K}=0.6-0.8)$; and almost perfect agreement $(\mathrm{K}>0.8)$ (Thrusfield, 1995).

\section{Data analysis}

All raw data generated from this study were coded and entered in MS Excel database system. Using SPSS version 16.0 computer program, data were analyzed. The prevalence of fasciolosis was calculated as the number of infected individuals divided by the number of individuals sampled $x 100$. Categorical data were analyzed with the Pearson's Chi-square $\left(\chi^{2}\right)$ test for independence whereas; oneway ANOVA was used to examine the differences between degrees of liver lesion with its fluke burden. Identification of the dominant Fasciola species was calculated using percentage. Statistical significance was set at $\mathrm{P}<0.05$ to determine whether there are significant differences between the parameters measured. 


\section{Results}

\section{Postmortem examination}

Out of 768 livers (of both cattle and sheep) examined, 239 (31.1\%) were found positive for fasciolosis. The prevalence of fasciolosis in cattle and sheep were $45.3 \%(\mathrm{n}=174)$ and $16.9 \%(\mathrm{n}=65)$, respectively. There was significant $\left(\chi^{2}=72.2 ; p\right.$ $=0.000$ ) variation in prevalence of fasciolosis between cattle and sheep (Table 1). Prevalence of ovine fasciolosis in male and female animals was $31(17.7 \%)$ and 34 $(16.3 \%)$, respectively. However, there was no significant $\left(\chi^{2}=0.14 ; p=0.710\right)$ variation in the prevalence of ovine fasciolosis between both sexes (Table 2). Prevalence of bovine fasciolosis in animals with poor body condition was 50.2\%. However, bovine with good body condition showed the prevalence of $38.1 \%$. There was significant variation $(\chi 2=50.51 ; p=0.019)$ in the prevalence of bovine fasciolosis between body condition scores (Table 3 ). In ovine, the prevalence of fasciolosis in animals with poor body condition was $37.1 \%$. However, ovine with good body condition showed the prevalence of $8.2 \%$. There was significant variation $(\chi 2=47.96 ; p=0.000)$ in the prevalence of ovine fasciolosis between body condition scores (Table 4 ).

Prevalence of fasciolosis in lambs was $13.7 \%(n=32)$. However, the prevalence of the disease in adult sheep was $21.8 \%(\mathrm{n}=33)$. There was significant variation $\left(\chi^{2}\right.$ $=4.3 ; p=0.038)$ in the prevalence of fasciolosis between age groups (Table 5).

Table 1. Prevalence of bovine and ovine fasciolosis based on liver examination

\begin{tabular}{lllll}
\hline Species & Examined & Prevalence $(\%)$ & $\chi 2$-value & $p$-value \\
\hline Cattle & 384 & $45.31 \%$ & 72.17 & 0.000 \\
Sheep & 384 & $16.93 \%$ & 7 & \\
\hline Total & 768 & $31.1 \%$ & &
\end{tabular}

Table 2. Prevalence of ovine fasciolosis based on sex

\begin{tabular}{lllll}
\hline Sex & Examined & Prevalence $(\%)$ & $\chi 2$-value & $p$-value \\
\hline Male & 175 & $17.7 \%$ & 0.15 & 0.710 \\
Female & 209 & $16.3 \%$ & & \\
\hline Total & 384 & $16.9 \%$ & & \\
\hline
\end{tabular}


Table 3. Prevalence of bovine fasciolosis based on body condition score

\begin{tabular}{lllll}
\hline BCS & Examined & Prevalence $(\%)$ & $\chi$ 2-value & $p$-value \\
\hline Poor & 229 & $50.2 \%$ & & \\
Good & 155 & $38.1 \%$ & 5.51 & 0.019 \\
\hline Total & 384 & $45.3 \%$ & & \\
\hline
\end{tabular}

Table 4. Prevalence of ovine fasciolosis based on body condition score

\begin{tabular}{lllll}
\hline BCS & Examined & Prevalence $(\%)$ & $\chi$ 2-value & $p$-value \\
\hline Poor & 116 & $37.1 \%$ & & \\
Good & 268 & $8.2 \%$ & 47.96 & 0.000 \\
\hline Total & 384 & $16.9 \%$ & & \\
\hline
\end{tabular}

Table 5. Prevalence of ovine fasciolosis by age

\begin{tabular}{lllll}
\hline Age & Examined & Prevalence $(\%)$ & $\chi$ 2-value & $p$-value \\
\hline Young & 233 & $13.7 \%$ & & \\
Adult & 151 & $21.9 \%$ & 4.30 & 0.038 \\
\hline Total & 384 & $16.9 \%$ & & \\
\hline
\end{tabular}

Fasciola species identification

From the total of 174 bovine infected livers, infections with $F$. hepatica and $F$. gigantica occurred with prevalence of $69.5 \%(\mathrm{n}=121)$ and $14.4 \%(\mathrm{n}=25)$, respectively, while mixed and unidentified species or immature fluke were $6.9 \%$ (n $=12)$ and $9.2 \%(\mathrm{n}=16)$ (Figure 1). Regarding ovine, from a total of 65 livers positive for the fluke, $50(70.9 \%)$ harbored $F$. hepatica, $9(13.9 \%) F$. gigantic, 2 $(3.1 \%)$ mixed infection by both flukes and $6(9.2 \%)$ harbored unidentified immature flukes (Figure 2).

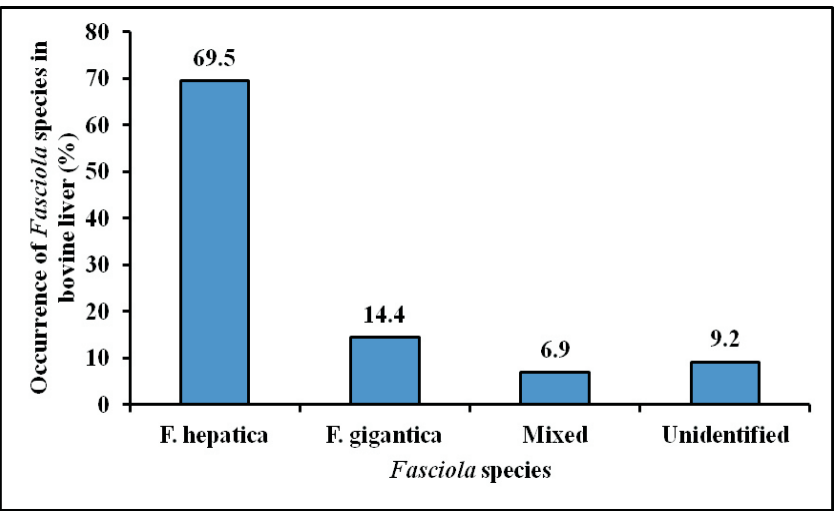

Figure 1. Identified Fasciola species and their relative abundance in bovine infected livers. 


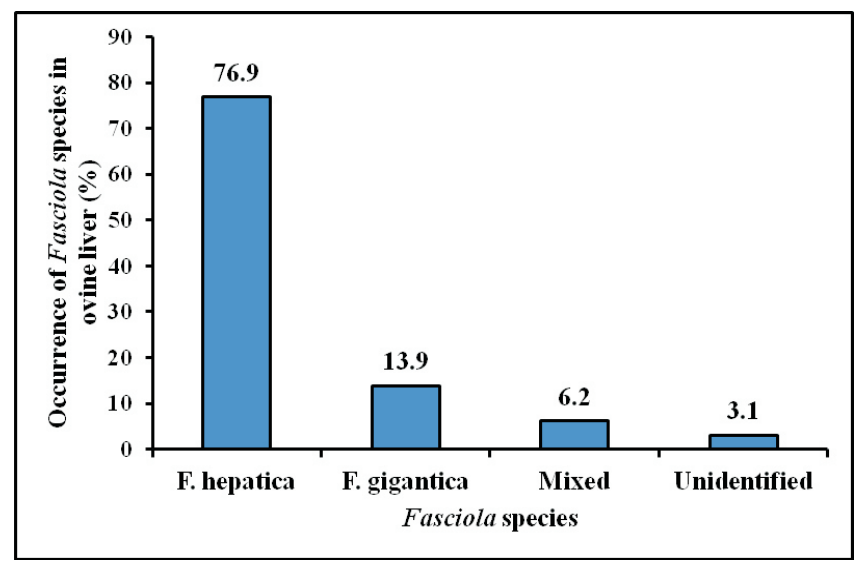

Figure 2. Identified Fasciola species and their relative abundance in ovine infected livers

\section{Liver fluke burden and degree of pathological lesions}

A total of 9155 flukes were recovered from the 174 infected bovine livers examined. Of these, 43 (24.7\%), 71 (40.8\%) and 60 (34.5\%) were affected lightly, moderately and severely, respectively. The overall fluke mean count was $52.61 \pm$ 23.77 (Figure 3). The average fluke count in moderately affected livers exceeded those obtained from lightly and severely affected livers $(\mathrm{P}=0.000)$.

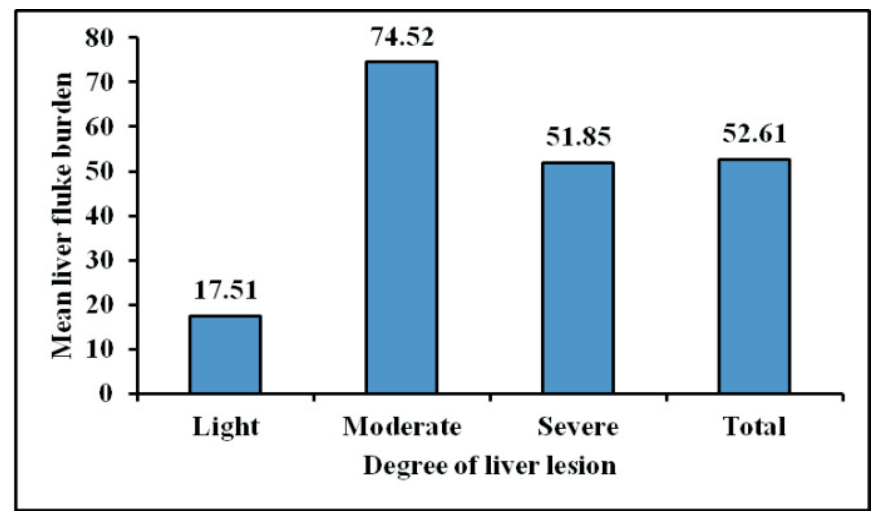

Figure 3. Relationship between mean fluke count and the corresponding liver lesions 
Comparison of diagnostic efficiency of faecal and liver examinations in bovine and ovine

The sensitivity and specificity of the direct sedimentation technique were calculated from the numbers of positive and negative tests in cattle and sheep with and without flukes in their livers, respectively (Smith, 1995). Taking postmortem examination as a gold standard technique for diagnosing Fasciola species infection, the sensitivity and specificity of bovine faecal examination were found to be $69.54 \%$ and $100 \%$, respectively (Table 6). Regarding ovine, the sensitivity and specificity were found to be $64.61 \%$ and $100 \%$, respectively (Table 7).

Table 6. The presence or absence of Fasciola species eggs in the faeces of cattle with and without fluke in the liver

\begin{tabular}{llll}
\hline Faecal examination & \multicolumn{3}{l}{ Presence of Fasciola species in bovine liver } \\
& Fluke present & Fluke absent & Total \\
\hline Eggs present & 121 & 0 & 121 \\
Eggs absent & 53 & 210 & 263 \\
\hline Total & 174 & 210 & 384 \\
\hline
\end{tabular}

Table 7. The presence or absence of Fasciola species eggs in the fae + ces of sheep with and without fluke in the liver

\begin{tabular}{llll}
\hline Faecal examination & \multicolumn{3}{l}{ Presence of Fasciola species in ovine liver } \\
& Fluke present & Fluke absent & Total \\
\hline Eggs present & 42 & 0 & 42 \\
Eggs absent & 23 & 319 & 342 \\
\hline Total & 65 & 319 & 384 \\
\hline
\end{tabular}

Assessment of direct economic loss due to bovine and ovine liver condemnation

The cost associated with condemnations of Fasciola-infected bovine and ovine livers were estimated to be 202,203.56 ETH Birr (11636.61 USD, calculated based on $1 \mathrm{USD}=17.3765 \mathrm{ETH}$ Birr assuming constant exchange rate throughout 2003 E.C, annually. The financial loss associated with bovine condemned livers alone was estimated to be 198,457.80 ETH Birr (11421.05 USD) annually. Financial loss due to ovine fasciolosis as a result of liver condemnation was also estimated to be 3,745.76 ETH Birr (215.56 USD) annually. 


\section{Discussion}

The finding of this study revealed the prevalence of bovine fasciolosis $(45.3 \%)$ to be higher than the prevalence of ovine fasciolosis (16.9\%). In support of this finding, the prevalence of $7.1 \%$ and $0.50 \%$ (Kadir and Rashid, 2008) in Iraq, $10.79 \%$ and $2.78 \%$ (Garg et al., 2009) in north India, 49.55\% and 28.70\% (Ahmadi and Meshkehkar, 2010) in Iran, and $8.6 \%$ and 3.1\% (Mellau et al., 2010) at Arusha, Tanzania in cattle and sheep, respectively was reported. Infected cattle livers were condemned more often than those of sheep. Normally, cattle are more prone to infections than sheep because of their grazing patterns in wet marshy areas favored by the fluke snail, but sheep prefer to graze away from marshy pastures, if feed is available elsewhere (Blood et al., 2007; Boray, 2007). Cattle suffer only from chronic form of fasciolosis whereas sheep suffer from acute form of the disease, which is associated with high mortality rates in sheep that prevent them from being slaughtered in abattoir (Mungube et al., 2006).

Prevalence of ovine fasciolosis in male and female animals was $17.7 \%$ and $16.3 \%$, respectively. There was no significant $(\chi 2=0.142 ; p=0.71)$ variation between both sexes of ovine, which agrees with reports of $13.4 \%$ in males and $13.2 \%$ in females (Ahmed et al., 2007) and $47.8 \%$ in males and $49.4 \%$ in females (Molalegne Bitew et al., 2010), indicating that sex seems to have no effect on the prevalence of the disease. This might be due to the fact that both sexes graze on similar pasture land. It might also be that the disease is not directly related to animal reproductive system (Graber and Daynes, 1974).

With regard to body condition of animals, the highest prevalence was observed in animals with poor body condition $(50.2 \%$ and $37.1 \%)$ both in bovine and ovine, respectively. In support of this finding specifically in bovine fasciolosis, a study conducted in Adwa, Ethiopia (Mihreteab Bekele et al., 2010) indicated a statistical significant association between the prevalence of fasciolosis and body condition of the animals. Reports of Ahmed et al. (2007) and Molalegne Bitew et al. (2010) conducted on ovine fasciolosis as well were in line with the current finding. Obviously, this could be due to the fact that animals with poor body condition are usually less resistant and are consequently susceptible to various diseases including fasciolosis.

Prevalence of fasciolosis in lambs and adults were $13.7 \%$ and $21.85 \%$, respectively, indicating that there was significant difference between age groups of ovine, which agrees with reports of $9.89 \%$ in the young and $14.9 \%$ in adults 
(Ahmed et al., 2007) and 29.3\% in the young and 56.4\% in adults (Molalegne Bitew et al., 2010). This study clearly showed a higher prevalence of fasciolosis in the old age group of sheep. This could be due to the fact that young animals are not allowed to go far with adult animals for grazing, reducing the chance of exposure to infective metacercaria as compared to adults (Molalegne Bitew et al., 2010). It has also been implicated that the higher exposure risk of adults compared to the young might be due to physiological differences, such as stress, pregnancy, lambing, inadequate nutrition, and infectious diseases (Ahmed et al., 2007).

Fasciola species identification in this study revealed $F$. hepatica to be the most prevalent $(69.5 \%$ and $70.9 \%$, in bovine and ovine, respectively) compared to $F$. gigantica $(14.4 \%$ and $15.9 \%)$, mixed infection by both species $(6.9 \%$ and $6.2 \%)$, and unidentified species $(9.2 \%$ and $3.1 \%)$. The high prevalence of $F$. hepatica clearly shows that most of the cattle for slaughter came from highland and middle altitude zones. This finding is in agreement with the reports of Tadelle Tollesa and Worku Tigre (2007); Gebretsadik Berhe et al. (2009); Mihreteab Bekele et al. (2010); Nuraddis Ibrahim et al. (2010); and Rahmeto Abebe et al. (2010). Studies in other countries of Africa, however, reported $F$. gigantica as a predominant species encountered in bovine and ovine (Phiri et al., 2006; Yabe et al., 2008). For instance, study on ovine fasciolosis in Arusha region, Tanzania, showed $F$. gigantic to be more dominant species than $F$. hepatica in affecting ovine livers (Mellau et al., 2010). The prevalence of fasciolosis and the occurrence of a specific type of Fasciola species are known to vary with locality. The highest prevalence of $F$. hepatica in the current study might be associated with the existence of favorable ecological biotopes for the snail, Lymnaea truncatula, in Ethiopia (Graber and Daynes, 1974). It has been reported that there exists variation in the degree of $F$. hepatica occurrence in all areas of the country except in the arid north-east and east of the country. F. gigantica has been reported to occur in the western zone of the country with localized foci in the south and east (Yilma Jobre and Malone, 1998). The same authors also reported co-existence of both species in areas with an altitude range of 1455-1700 metres above sea level (masl).

In the present study, the findings of an average 52.61 flukes per affected livers imply the presence of high pathogenicity of flukes in the studied animals. This finding agrees with Yilma Jobre and Mesfin Ali (2000), Mihreteab Bekele et al. (2010), and Rahmeto Abebe et al. (2010) who reported a relatively less flukes in severely affected livers of cattle. It seems that combined effect of severe liver fibrosis, calcification of bile ducts, and acquisition of resistance plays a major role in creating unfavorable micro-environment which results in the expulsion of flukes. 
The sensitivity of the sedimentation diagnostic technique in bovine was comparable to the reports of $67.13 \%$ at Hawassa, Ethiopia, municipal abattoir (Rahmeto Abebe et al., 2010) and 69\% in Switzerland (Rapsch et al., 2006). The latter stated that traditional coproscopy can be very efficient if there is repeated sampling, resulting in sensitivity of approximately $92 \%$. Nevertheless, faecal examination alone is not enough for the diagnosis of fasciolosis. Additionally, postmortem liver inspection has been suggested to be employed for accurate assessment of the prevalence of fasciolosis in ovine and bovine (Kaufmann, 1996).

The present financial loss in bovine-infected livers in the study area was higher than the reports of Taddele Tollesa and Worku Tigre (2007), Fufa Abunna et al. (2009), Gebretsadik Berhe et al. (2009), Mihreteab Bekele et al. (2010), Nuraddis Ibrahim et al. (2010) and Rahmeto Abebe et al. (2010) that reported financial losses of 6,300 USD from Jimma municipal abbatoir, 4,000 USD at Soddo municipal abattoir, 95,355.20 ETH Birr at Mekelle municipal abattoir, 4,672 USD at Adwa municipal abattoir, 1,833 USD at Kombolcha industrial and municipal abattoir and 106,400 ETH Birr at Hawassa municipal abattoir, respectively. Regarding in sheep, the present financial loss due to infected livers in the study area was higher than 2.27 USD in the middle Awash River basin (Ahmed et al., 2007).

\section{Conclusion}

The level of infection observed in this study suggests the existence of favorable climatic conditions throughout the year for the development and survival of the parasite in the area of origin of the studied animals due to the water lodgment from Lake Tana and Blue Nile River. Animals with poor body condition were found highly infected by fasciolosis than animals with good body condition. Sex had no effect on the prevalence of fasciolosis. Age wise, however, adults were found to be highly infected than their younger counterparts. The most prevalent Fasciola species obtained in condemned livers was Fasciola hepatica in and around Bahir Dar. There was substantial agreement between faecal examination and liver inspection in the diagnosis of fasciolosis. The financial loss related with the condemnation of Fasciola infected livers at the abattoir also indicated the economic importance of fasciolosis in the study area. It is therefore concluded that fasciolosis causes significant losses to farmers, butchers and consumers. 


\section{Acknowledgements}

The authors of this paper would like to thank Biology Department, Bahir Dar University and Bahir Dar Regional Veterinary Laboratory for allowing us to use their facilities.

\section{References}

Abebe, R., Abunna, F., Berhane, M., Mekuria, S., Megersa, B. and Regasa, A., 2010. Prevalence, financial losses due to liver condemnation and evaluation of a simple diagnostic technique in cattle slaughtered at Hawassa Municipal abattoir, southern Ethiopia. Ethiop. Vet. J., 14, 39-51.

Abunna, F., Asfaw, L., Megersa, B. and Regasa, A., 2010. Bovine fasciolosis: coprological, abattoir survey and its economic impact due to liver condemnation at Soddo municipal abattoir, Southern Ethiopia. Trop. Anim. Hlth. Prod., 42, 289-292.

Ahmadi, N. A. and Meshkehkar, M., 2010. Prevalence and long term trend of liver fluke infections in sheep, goats and cattle slaughtered in Khuzestan, southwestern Iran. $J$. Paramed. Sci., 1, 26-31.

Ahmed, E. F., Markvichitr, S., Tumwasorn, S, Koonawootrittriron, A., Choothesa, A. and Jittapalapong, S., 2007. Prevalence of Fasciola spp. infections of sheep in the middle Awash River basin, Ethiopia. Southeast Asian J. Trop. Med. Pub. Hlth., 38, 51-57.

Andrews, S. J., 1999. The life cycle of Fasciola hepatica. In: Dalton, J.P. (Ed.), CABI Publishing, Walling ford, UK, pp. 1-30.

Bekele, M., Teklay, H. and Getachew, Y., 2010. Prevalence and its economic loss due to liver condemnation at Adwa Municipal abattoir, north Ethiopia. EJAST, 1, 39- 47.

Berhe, G., Birhane, K. and Tadesse, G., 2009. Prevalence and economic significance of fasciolosis in cattle in Mekelle area of Ethiopia. Trop. Anim. Hlth. Prod., 41, 15031504 .

Bitew, M., Ibrahim, N., and Abdela, N., 2010. Study on the prevalence of ovine fasciolosis in and around Dawa-Cheffa, Kemissie. Afr. J. Agr. Res., 5, 2981-2985.

Blood, D. C., Radostits, O. M., Gay, C. C., Hinchcliff, K. W. and Constable, P. D., 2007. Veterinary Medicine: A textbook of the diseases of cattle, horses, sheep, pigs and goats. $10^{\text {th }}$ edition, Saunders Ltd, p. 2065.

Boray, J. C., 2007. Liver fluke disease in sheep and cattle. PRIME FACT 446, pp. 1-10. 
FAO (Food and Agricultural Organization), 1994. 'World agriculture towards 2015/30', Food and Agriculture Organization of the United Nations (FAO), Rome.

FAO, 2003. Diagnostic Manual on Meat Inspection for Developing Countries.

Garg, R., Yadav, C. L., Kumar, R. R., Banerjee, P. S., Vatsya, S. and Godara, R., 2009. The epidemiology of fasciolosis in ruminants in different geo-climatic regions of north India. Trop. Anim. Hlth. Prod., 41, 1695-1700.

Graber, M. and Daynes, P., 1974. Mollusques vecteurs de trematodoses humaines et animales en Ethiopie. Revue Med. Vet. Trop., 27, 307-322.

Hammond, J. A. and Swell, M. H., 1974. Loatation on to Sellotape (demonstration). Trans. R. Soc. Trop. Med. Hyg., 66, 547.

Hansen, J. and Perry, B., 1994. The Epidemiology, Diagnosis and Control of Helminth Parasites of Ruminants: A Handbook. Animal Production and Health Division, FAO, Rome, Italy. P. 171.

Hillyer, G. V. and Apt, W., 1997. Food-borne trematode infections in the Americas. Parasitol. Today, 13, 87-88.

Ibrahim, N., Wasihun, P and Tollesa, T., 2010. Prevalence of bovine fasciolosis and economic importance due to liver condemnation at Kombolcha industrial abattoir, Ethiopia. The Internet J. Vet. Med. 8(2).

Jibat, T., Ejeta, G., Asfaw, Y. and Wudie, A., 2008. Causes of abattoir condemnation in apparently healthy slaughtered sheep and goats at HELMEX abattoir, Debre Zeit, Ethiopia. Revue Med. Vet., 159, 305-31.

Jobre, Y. and Malone, J. B., 1998. A geographical information system forecast model for strategic control of fasciolosis in Ethiopia. Vet. Parasitol., 78, 103-127.

Jobre, Y. and Ali, M., 2000. Dry season bovine fasciolosis in Northwestern part of Ethiopia. Revue Med. Vet., 151, 493-500.

Kadir, M. A. and Rasheed, S. A., 2008. Prevalence of some parasitic helminths among slaughtered ruminants in Kirkuk slaughter house, Kirkuk, Iraq. Iraqi J. Vet. Sci., 22, $81-85$.

Kaufmann, J., 1996. Parasitic Infection of Domestic Animal. A Diagnostic Manual, Birhouser Verlag Berlin, pp. 90-92. 
Keyyu, J. D., Kassuku, A. A., Msalilwa, L. P., Monrad, J. and Kyvsgaard, N. C., 2006. Cross- sectional prevalence of helminth infection in cattle on traditional, small -scale and large-scale dairy farms in Iringa district, Tanzania. Vet. Res. Commun., 30, 45-55.

Lemma, B., 1983. The seasonal occurrence of fasciolosis and some other helminthic diseases of sheep in four-selected sites of Ethiopia. M.Sc. Thesis, AAU, Addis Ababa. pp. 106.

Malone, J. B., Gommes, R., Hansen, J., Jobre, Y., Slingenberg, J., Snijders, F., Nachtergeale, F. and Ataman, E., 1998. A geographic information system on the potential distribution and abundance of $F$. hepatica and F. gigantica in east Africa based on Food and Agriculture Organization databases. Vet. Parasitol., 78, 87-101.

Mellau, L. S. B., Nonga, H. E. and Karimuribo, E. D., 2010. A slaughter survey of liver lesions in slaughtered cattle, sheep and goat at Arusha, Tanzania. Res. J. Vet. Sci., 3, 179-188.

Mungube, E. O., Bauni, S. M., Tenhagen, B. A., Wamae, L. W., Nginyi, J. M. and Mugambi, J. M., 2006. The prevalence and economic significance of Fasciola gigantica and Stilesia hepatica in slaughtered animals in the semi-arid coastal Kenya. Trop. Anim. Hlth. Prod., 38, 475-483.

Nicholson, M.J. and Butterworth, M.H., 1986. A guide to condition scoring of zebu cattle. International Livestock Center for Africa-ILCA, Addis Ababa, Ethiopia.

Ogunrinade, A. and Ogunrinade, BI., 1980. Economic importance of fascioliasis in Nigeria. Trop. Anim. Hlth. Prod., 12, 155-160.

Ogunrinade, A. and Adegoke, G. O., 1982. Bovine fascioliasis in Nigeria. Intercurrent parasitic and bacterial infection. Trop. Anim. Hlth. Prod., 14, 121-125.

Phiri, A. M., Phii, I. K., Sicasungel, C. S., Chembensofu, M. and Monrad, J., 2006. Comparative fluke burden and pathology in condemned and non-condemned cattle livers from selected abattoirs of Zambia. Onderstepoort J. Vet. Res., 73, 275-281.

Rapsch, C., Schweizer, G., Grimm, F., Kohler, L., Bauer, C., Deplazes, P., Braun, U. and Torgerson, P. R., 2006. Estimating the true prevalence of Fasciola hepatica in cattle slaughtered in Switzerland in the absence of an absolute diagnostic test. Int. J. Parasitol., 36, 1153-1158.

Smith, R. D., 1995. Veterinary Clinical Pathology. A problem Oriented Approach, $2^{\text {nd }}$ edition, CRC Press, Boca Raton, FL, pp. 31-52.

Soulsby, E. J. L., 1982. Helminth, Arthropod and Protozoa of Domestic Animals, $7^{\text {th }}$ edition, Baillere Tindall, London, UK, pp. 40-52. 
Thompson, J. and Meyer, H., 1994. Body condition scoring of sheep. http://eesc.orst. edu/agco comwebfile/edmat/EC1433.

Thrusfield, M., 1995. Veterinary Epidemiology, $2^{\text {nd }}$ edition, University of Edinburgh, BlackWell Science Ltd, Oxford, UK, pp. 180-188.

Tollesa, T. and Tigre, W., 2007. The prevalence and economic significance of bovine fasciolosis at Jimma, abattoir, Ethiopia. The Internet J. Vet. Med., 3, 1937-1943.

Urquhart, G. M., Armour, J., Duncan, J. L., Dunn, A. M. and Jennings, F.W., 1996. Veterinary Parasitology, $2^{\text {nd }}$ edition. Oxford, Longman Scientific and Technical Press, UK, pp. 100-109.

WHO, 1995. Control of food borne trematode infections. Technical Report Series 849, pp. 61.

Yabe, J., Phiri, I. K., Phiri, A. M., Chembensofu, M., Dorny, P. and Vercruysse, J., 2008. Concurrent infections of Fasciola, Schistosoma and Amphistomum species in cattle from Kafu and Zambezi river basins of Zambia. J. Helminthol., 98, 1-4. 